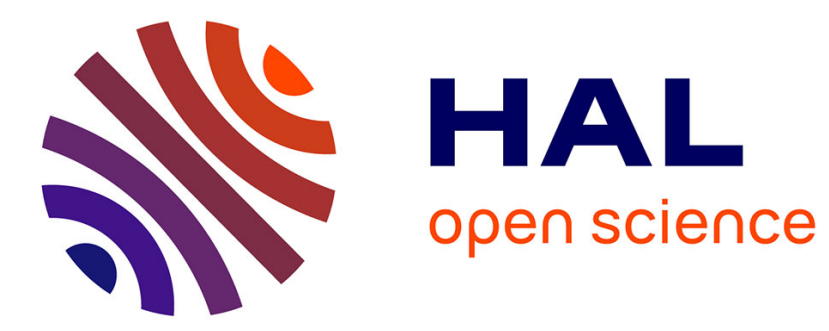

\title{
Normative health-related fitness values for French children: The Diagnoform Programme
}

\author{
Jeremy Vanhelst, Camille Ternynck, Hervé Ovigneur, Thibault Deschamps
}

\section{To cite this version:}

Jeremy Vanhelst, Camille Ternynck, Hervé Ovigneur, Thibault Deschamps. Normative health-related fitness values for French children: The Diagnoform Programme. Scandinavian Journal of Medicine and Science in Sports, 2019, 30 (4), pp.690-699. 10.1111/sms.13607 . hal-03154812

\section{HAL Id: hal-03154812 \\ https://hal.univ-lille.fr/hal-03154812}

Submitted on 1 Mar 2021

HAL is a multi-disciplinary open access archive for the deposit and dissemination of scientific research documents, whether they are published or not. The documents may come from teaching and research institutions in France or abroad, or from public or private research centers.
L'archive ouverte pluridisciplinaire HAL, est destinée au dépôt et à la diffusion de documents scientifiques de niveau recherche, publiés ou non, émanant des établissements d'enseignement et de recherche français ou étrangers, des laboratoires publics ou privés. 
Title: Normative health-related fitness values for French children: The Diagnoform Programme

Running head: Physical fitness reference

Jérémy Vanhelst ${ }^{1}$, Camille Ternynck ${ }^{2}$, Hervé Ovigneur ${ }^{3}$, Thibault Deschamps ${ }^{3}$ 


\begin{abstract}
The primary objective of this study was to establish sex- and age-specific physical fitness percentiles for French children. The secondary aim was to assess sex, weight status and age differences for physical fitness levels in French children. A sample of 31,484 children $(16,023$ boys, 15,461 girls) aged 6-11 years participated in the Diagnoform programme. Cardiorespiratory fitness, muscular endurance, speed, flexibility and agility were assessed in this national programme. Percentile values were estimated as a function of age stratified by sex using a parametric method providing smooth centile curves and explicit formulae for the centile estimates. Values from the $10^{\text {th }}$ to the $90^{\text {th }}$ percentile are reported. The influence of body weight according to sex on the physical fitness level was also examined using an analysis of covariance adjusted for age. Physical fitness levels were slightly better in boys, except for agility and flexibility, in which girls performed better (Cohen's coefficient, 0.20 $0.45 ; p<0.001)$. All physical fitness tests were significantly associated with age $(p<0.0001)$. In general, overweight and obese children had a significantly poorer physical fitness level compared with their normal-weight counterparts $(p<0.05)$. No difference was found between thin and normal-weight boys and girls, except for agility $(p<0.05)$. Reference values provide normative data for French children, and these data should be useful for identifying special needs for appropriate intervention programmes.
\end{abstract}

Keywords: Physical fitness; Children, Health, Percentiles 


\section{INTRODUCTION}

Physical fitness is now widely recognized as an important determinant of health in children and adolescents. ${ }^{1}$ Health-related physical fitness includes muscular strength, speed/agility and cardio-respiratory fitness. ${ }^{1}$ Many studies have shown that each physical fitness component has a positive effect on the health status in young people. ${ }^{1-3}$ It has been suggested that cardiorespiratory fitness levels are associated with total and abdominal adiposity, and both cardiorespiratory and muscular fitness have been shown to be associated with established and emerging cardio-vascular disease risk factors. Moreover, improvements in muscular fitness and speed/agility have a positive impact on bone health, and both cardio-respiratory and muscular fitness enhancements have been shown to improve the quality of life in paediatric cancer patients, as well as having positive effects on mental health, self-esteem and academic performance. ${ }^{1-3}$ In two cohort studies performed in Swedish male adolescents, it was noted that low muscular strength and cardio-respiratory fitness were strong risk factors for major causes of death in young adulthood (suicide and cardio-vascular diseases), equivalent to other risk factors such as elevated body mass index (BMI) or blood pressure. ${ }^{4-5}$ For all these reasons, there is a real need to develop surveillance monitoring of physical fitness in children and adolescents.

Sex- and age-specific normative values are necessary to assess and interpret fitness status in children and adolescents. Moreover, establishing percentiles in youth is essential for screening children and adolescents according to their growth in comparison with those of the same age and sex. Fitness reference values in children and adolescents have been reported in many countries in Europe, the Americas, Oceania and Asia. ${ }^{6-20}$ Recently, Tomkinson established European normative values for several physical fitness components in youth aged 9-17 years. ${ }^{21}$ However, data on physical fitness levels in France are scarce, and only one study addressing the reference data for a French sample has been reported, and that study was restricted to adolescents. ${ }^{20}$ 
The primary objective of this study was to establish sex- and age-specific physical fitness percentiles for French children aged 6-11 years. The secondary aim was to assess sex, weight status and age differences for the physical fitness levels in French children.

\section{METHODS}

This cross-sectional study was based on data from the French health programme Diagnoform ${ }^{\circledR}$ (https://irfo.fr/). The principal aim of this national programme is to assess the physical fitness of a large sample of the French population from the age of 5 years. The programme is divided in four categories: (i) DiagnoKid for children aged 5-10 years; (ii) DiagnoTonic for adolescents and young adults aged 10-25 years; (iii) DiagnoActif for adults aged 25-60 years; and (iv) DiagnoSanté for those aged $>60$ years. The programme is carried out in large settings such as school playgrounds or sports club gymnasiums throughout France.

For the present study, data analysis was performed only with the DiagnoKid battery. Data were collected in several regions of France between 2010 and 2018 (see Supplementary file 1). All schools in France were invited to participate in the study, with each school director deciding whether to participate or not. If the invitation was accepted, the children were invited to participate. All data obtained from the organizer (Institut des Rencontres de la Forme) of the event were anonymized, and declared and approved by the Commission Nationale de l'Informatique et des Libertés (National Commission on Informatics and Liberty). The study objectives were explained carefully to both children and their parents, after which the children or their parents could accept or decline to participate in the study and to record anonymously their information technology data. Data were recorded by the organizer in an electronic data system. An audit of the complete dataset was performed, and aberrant data were excluded.

\section{Measurements}




\section{Participant characteristics}

Body weight was measured with the participant wearing light clothes and without shoes to the nearest $0.1 \mathrm{~kg}$ using an electronic scale. Height was measured without shoes to the nearest 0.1 cm using a standard physician's scale. BMI was calculated as weight $/ \mathrm{height}^{2}\left(\mathrm{~kg} / \mathrm{m}^{2}\right)$. The nutritional status was assessed using the International Obesity Task Force (IOTF) scale. ${ }^{22}$

\section{Physical fitness}

The health-related physical fitness components were assessed using the Diagnoform battery tests, incorporating some Eurofit battery tests. ${ }^{23}$ This battery of tests assesses cardiorespiratory fitness, muscular strength (lower limbs), speed, flexibility and agility (see Supplementary file 2). All tests were performed once. Good reliability and validity in young people have been reported for all tests used in the present study. ${ }^{24-25}$ Measurements were performed by the organizer and by other investigators who undertook special training to ensure that tests were administered correctly.

\section{Cardio-respiratory fitness}

The cardio-respiratory test was measured by a 20 -m shuttle run-walk test during 6 min. $^{25}$ This test has been validated against the 20-m shuttle run reference test from Leger et al (1988) $(\mathrm{r}=$ $0.78 ; p=0.001) .{ }^{25}$ Children were instructed to run and walk as far as possible between two lines located $20 \mathrm{~m}$ apart during $6 \mathrm{~min}$. The children ran as quickly as possible from the starting line to the other line and returned to the starting line at a fast walking pace, crossing each line with at least one foot throughout the complete test. The test began on the whistle and was concluded after $6 \mathrm{~min}$. The distance covered by the child was recorded and is expressed in $\mathrm{m}$.

\section{Muscular strength}


Muscular strength for lower limbs was assessed by the standing broad jump test. From a starting position immediately behind a line, standing with the feet approximately shoulder width apart, children jumped as far as possible with their feet together. The result was recorded in $\mathrm{cm}$. A nonslip hard surface, chalk and a tape measure were used to perform the test.

\section{Speed}

Speed was assessed by running as fast as possible for $5 \mathrm{~s}$. The children stood still in a comfortable position, feet behind the starting line, with no rocking movement. The test began on the whistle and was concluded when the countdown reached zero. The distance covered by the runner was recorded by a mark on the ground and is expressed in $\mathrm{m}$.

\section{Flexibility}

Flexibility was assessed by a test measuring leniency and the capability to reach down as far as possible. From a standing position and with both legs straight, the children flexed their trunk and reached down as far as possible with their hands. Children maintained the position for 3 s. Results of this test were indexed: a score of 5 for placing the hands flat on the ground; 4 for fingers touching the ground; 3 for fingers reaching the ankle; 2 for fingers reaching the tibia; and 1 for fingers/hands reaching the knees.

\section{Agility}

Agility was assessed using the hopscotch test. Children stood still in a comfortable position, with their feet behind the starting line, and with no rocking movements. They then performed the hopscotch test as quickly as possible. The stopwatch was stopped when the child crossed the end line with both feet. The time taken to complete the test was recorded to the nearest tenth of a second. 


\section{Statistical analysis}

Subject characteristics are described as mean $\pm \mathrm{SD}$, median and interquartile interval, or number (percentage). The influence of body weight on the physical fitness level was examined in boys and girls separately using an analysis of covariance model (or an ordinal logisitic regression) adjusted for age. In this model, covariates were age, sex, weight status (using the IOTF definition), and sex*weight status. Post hoc pairwise comparisons using normal weight as reference were performed using linear contrasts after applying Bonferroni correction.

To examine the association between age and each measurement of interest, and to investigate the need to provide age-specific reference intervals by sex, we used a non-parametric smoothing technique (loess regression). Age-specific reference intervals for each measurement of interest were constructed from the parametric method proposed by Royston and Wright (1998) providing smooth centile curves and explicit formulae for the centile estimates. ${ }^{26}$ Further details about this method are available in Supplementary file 3. All analyses were computed using R software (version 3.5.2) and SAS software (version 9.4, SAS Institute Inc, Cary, NC, USA).

\section{RESULTS}

A total of 32,132 volunteers aged 4-17 years participated in the Diagnoform battery tests. Because of the small sample size of participants aged 4, 5 and 12-17 years compared with other age-sex classes, we restricted the analysis to 31,484 participants aged 6-11 years. Physical fitness measurements for the study sample are reported by age and sex in Table 1 . Overall, physical fitness levels were better in boys, except for agility and flexibility, in which girls performed better $(p<0.05)$. Differences for each component of physical fitness between 
boys and girls were small (Cohen's effect size, 0.2-0.5) (Table 1). All physical fitness tests were significantly associated with age $(p<0.0001)$. Scores obtained in physical fitness tests by boys and girls increased with increasing age.

Physical fitness according to weight status in boys and girls is presented in Figures 1 and 2 and Supplementary file 4. In general, overweight and obese boys had significantly poorer physical fitness (cardio-respiratory, muscular strength, agility and speed) compared with normal-weight boys $(p<0.05$; Figure 1). Similar results were found for overweight and obese girls (Figure 1). For flexibility, obese boys and girls had significantly lower scores than normal-weight boys and girls. Differences found between overweight and normal-weight boys and girls were small for all physical fitness components (Cohen's effect size, 0.2-0.5) (Supplementary file 4). Between obese and normal-weight girls, differences found were moderate for cardio-respiratory fitness, muscular strength and speed, and small for agility (Supplementary file 4). Between obese and normal-weight boys, differences found were large for cardio-respiratory fitness and muscular strength, moderate for speed, and small for agility (Supplementary file 4). No difference was found between thin and normal-weight boys and girls, except for agility, in which thin children performed better $(p<0.05$; Figure 1). However, this difference was negligible (Cohen's effect size, $<0.2)$ (Supplementary file 4). Sex- and age-specific percentile values $\left(10^{\text {th }}, 20^{\text {th }}, 30^{\text {th }}, 40^{\text {th }}, 50^{\text {th }}, 60^{\text {th }}, 70^{\text {th }}, 80^{\text {th }}\right.$ and $90^{\text {th }}$ percentiles) for the different physical fitness measurements are reported in Tables 2-5, and the derived smoothed centile curves are shown in Supplementary file 5.

\section{DISCUSSION}

Establishing percentile values for physical fitness tests may help to identify the target population for primary prevention and may be useful for health promotion policies. The French health programme Diagnoform ${ }^{\circledR}$ provides an opportunity to establish, for the first 
time, normative values for fitness components (i.e., cardio-respiratory fitness, muscular strength, speed, flexibility and agility) in French children.

The first finding from our study is that physical fitness levels were better in boys compared with girls, except for agility and flexibility, which agrees with results previously reported in children and adolescents. ${ }^{13-16,20,27-29}$ These differences may be attributed to the distinct development, growth and maturation of boys and girls. ${ }^{30}$ In addition, cultural, social and environmental factors may affect the development of motor performance and physical activity lifestyle. Studies have reported that boys show better performance than girls in cardiorespiratory fitness and muscular strength because they are more physically active and have a higher fat-free mass. ${ }^{31-32}$

Another outcome from our study is that physical fitness levels are associated with age. For boys and girls, the performance in physical fitness tests increased with increasing age. While studies of adolescents have shown a stagnation or decrease in physical fitness with age, an improvement in physical fitness with increasing age is reported in children. ${ }^{14,28,33}$ Our results suggest that older children have better motor competency compared with young children. Berk suggests that motivation, concentration, the degree of motor skills, physical activity and body composition could also be factors that explain this difference. ${ }^{34}$

Regarding weight status differences, overweight and obese children (both boys and girls) have significantly poorer physical fitness levels compared with their normal-weight counterparts. The impact of overweight and obesity on physical fitness in children has been extensively studied..$^{31,35-38}$ The results from our study of French children confirm those of previous research indicating a negative relationship between weight status and fitness in children and adolescents. ${ }^{31,35-38}$ Body composition, especially fat mass, could have an influence on results. One study suggests that excess body fat determined a lower performance in all tests requiring propulsion or lifting of the body mass, because the association became non-significant or was 
transformed into the opposite association after adjusting for fat mass. ${ }^{31}$ It was concluded that when fat mass differences are taken into account, overweight and obese adolescents do not show a lower performance in weight-bearing physical fitness tests. ${ }^{31}$ In contrast, physical fitness in thin youths has been far less studied. ${ }^{31,39-41}$ In our study, no difference was found between thin and normal-weight participants in physical fitness tests, except for agility: thin boys and girls had a better score in the agility test compared with their normal-weight counterparts. Studies examining the relationship between weight status and health-related physical fitness in youth have often reported a decrease in fitness with increasing BMI. ${ }^{31,39-41}$ Methodological differences in the physical fitness tests chosen might explain the discrepancies between the present study and previous findings. In addition, the hopscotch test used in our study to assess agility might explain the better performance of thin children compared with those of normal weight. Although thin children may have lower muscular strength, their body weight is lower. Thus, the hopscotch test may be considered as weight dependent. Our results suggest that the higher performance of thin adolescents resulting from their lower load to be moved could be counteracted by their lower fat-free mass.

Given that data on reference standards of fitness levels in French children are lacking, various aspects of the results from our study showing sex- and age-specific normative values for physical fitness tests are relevant. A fitness level below the $10^{\text {th }}$ percentile may be considered as deleterious for health because low scores on cardio-respiratory fitness and muscular strength are associated with increasing cardio-vascular risks. ${ }^{1-3}$ Even if our data on reference standards in this study are not directly associated with biological markers of cardio-vascular risks, we recommend the monitoring of children with a fitness level below the $30^{\text {th }}$ percentile for health promotion and intervention programmes. Our reference values can also be used to assess children's performance by health care practitioners, schools, sport clubs and by the children themselves. We propose that performance level may decline along a specific scale 
according to the following reference values: very low $\left(\mathrm{X}<10^{\text {th }}\right.$ percentile); low $\left(10^{\text {th }}\right.$ percentile $\leq X<30^{\text {th }}$ percentile $)$; medium $\left(30^{\text {th }}\right.$ percentile $\leq X<70^{\text {th }}$ percentile $)$; high $\left(70^{\text {th }}\right.$ percentile $\leq X<90^{\text {th }}$ percentile); and very high $\left(X \geq 90^{\text {th }}\right.$ percentile $)$.

The current study has both strengths and limitations. Major strengths include the large sample of children from across France with sex-specific information, and the harmonization and standardization of assessment of physical fitness. The main limitation of the study is the cross-sectional design. Because of the changes in individual growth and maturation in children and adolescents, physical fitness reference values should be obtained from a longitudinal study with repeated measurements. Moreover, even if our study allows for the accurate detection of individual improvements, further studies should be performed to more fully characterize and identify cut-off points related to health outcomes for cardio-respiratory fitness, muscular strength, speed and agility. Finally, although the present data derive from a large sample across France, this study did not use a stratified sample design. Therefore, it is not possible to assume that the studied cohort is fully representative of the populations of French children and adolescents.

\section{PERSPECTIVES}

In summary, for the first time, our study provides sex- and age-specific physical fitness percentiles for French children aged 6-11 years old. Our findings complement those of Vanhelst et al (2017) in adolescents aged 10-15 years. ${ }^{20}$ These reference standards are of particular interest to teachers and health care practitioners in the development of intervention programmes for children identified with low physical fitness status. 


\section{REFERENCES}

1. Ortega FB, Ruiz JR, Castillo MJ et al. Physical fitness in childhood and adolescence: A powerful marker of health. Int J Obes 2008; 32(1): 1-11.

2. García-Hermoso A, Ramírez-Campillo R, Izquierdo M. Is muscular fitness associated with future health benefits in children and adolescents? A systematic review and meta-analysis of longitudinal studies. Sports Med 2019; 49(7): 1079-94.

3. Smith JJ, Eather N, Morgan PJ et al. The health benefits of muscular fitness for children and adolescents: a systematic review and meta-analysis. Sports Med 2014; 44(9): 1209-23.

4. Ortega FB, Silventoinen K, Tynelius $P$ et al. Muscular strength in male adolescents and premature death: cohort study of one million participants. BMJ 2012; 345: e7279.

5. Högström G, Nordström A, Nordström P. Aerobic fitness in late adolescence and the risk of early death: a prospective cohort study of 1.3 million Swedish men. Int J Epidemiol 2016; 45(4): 1159-68.

6. Catley MJ, Tomkinson GR. Normative health-related fitness values for children: Analysis of 85347 test results on 9-17-year-old Australians since 1985. Br J Sports Med 2013; 47(2): 98-108.

7. Castro-Pinero J, Gonzalez-Montesinos JL, Mora $\mathrm{J}$ et al. Percentile values for muscular strength field tests in children aged 6 to 17 years: Influence of weight status. $J$ Strength Cond Res 2009; 23(8): 2295-2310.

8. Castro-Pineiro, J, Ortega, FB, Keating, XD et al. Percentile values for aerobic performance running/walking field tests in children aged 6 to 17 years: Influence of weight status. Nutr Hosp 2011; 26(3): 572-578.

9. Eisenmann, JC, Laurson, KR, Welk, GJ. Aerobic fitness percentiles for U.S. adolescents. Am J Prev Med 2011; 41(4 SIpp 2): S106-S110.

10. Lee S, Ko BG, Park S. Physical Fitness Levels in Korean Adolescents: The National Fitness Award Project. J Obes Metab Syndr 2017; 26(1): 61-70.

11. Ramos-Sepúlveda JA, Ramírez-Vélez R, Correa-Bautista JE et al. Physical fitness and anthropometric normative values among Colombian-Indian schoolchildren. BMC Public Health 2016; 13(16): 962.

12. Hobold E, Pires-Lopes V, Gómez-Campos R et al. Reference standards to assess physical fitness of children and adolescents of Brazil: an approach to the students of the Lake Itaipú region-Brazil. PeerJ 2017; 30(5): e4032.

13. Secchi JD, García GC, España-Romero V et al. Physical fitness and future cardiovascular risk in argentine children and adolescents: an introduction to the ALPHA test battery. Arch Argent Pediatr 2014; 112(2): 132-140. 
14. Tambalis KD, Panagiotakos DB, Psarra G et al. Physical fitness normative values for 618-year-old Greek boys and girls, using the empirical distribution and the lambda, mu, and sigma statistical method. Eur J Sport Sci 2016; 16(6): 736-746.

15. De Miguel-Etayo P, Gracia-Marco L, Ortega FB et al. Physical fitness reference standards in European children: the IDEFICS study. Int J Obes 2014; 38 (Suppl 2): S57-66.

16. Saint-Maurice PF, Laurson KR, Kaj M et al. Establishing normative reference values for standing Broad Jump among Hungarian youth. Res Q Exerc Sport 2015; 86(5): S37-S44.

17. Saint-Maurice PF, Laurson KR, Karsai I et al. Establishing normative reference values for Handgrip among Hungarian youth. Res Q Exerc Sport 2015; 86(5): S29-S36.

18. Sandercock G, Voss C, Cohen D et al. Centile curves and normative values for the twenty metre shuttle-run test in English schoolchildren. J Sports Sci 2012; 30(7): 679-687.

19. Santos R, Mota J, Santos DA, Silva AM, Baptista F, Sardinha LB. Physical fitness percentiles for Portuguese children and adolescents aged 10-18 years. J Sports Sci 2014; 32(16): 1510-1518.

20. Vanhelst J, Labreuche J, Béghin L et al. Physical Fitness Reference Standards in French Youth: The BOUGE Program. J Strength Cond Res. 2017; 31(6):1709-1718.

21. Tomkinson GR, Carver KD, Atkinson $\mathrm{F}$ et al. European normative values for physical fitness in children and adolescents aged 9-17 years: results from 2779165 Eurofit performances representing 30 countries. Br J Sports Med 2018; 52(22): 1445-14563.

22. Cole TJ, Bellizzi MC, Flegal KM et al. Establishing a standard definition for child overweight and obesity worldwide: international survey. BMJ 2000; 320(7244): 1240-1243.

23. Council of Europe. Testing Physical Fitness EUROFIT Experimental Battery: Provisional Handbook. Strasbourg, France: The Council, 1983.

24. Ortega FB, Artero EG, Ruiz JR et al. Reliability of health-related physical fitness tests in European adolescents. The HELENA study. Int J Obes 2008; 32(Supp15): S49-S57.

25. Mouraby R, Tafflet M, Nassif $\mathrm{H}$ et al. Reliability and validity of Diagnoform fitness test procedure. Science Sports 2012; 27(3): 50-53.

26. Royston P, Wright EM. A method for estimating age-specific reference intervals ('normal ranges') based on fractional polynomials and exponential transformation. J Royal Stat Society: Series A; 1998; 161(1): 79-101.

27. Golle K, Muehlbauer T, Wick D, Granacher U. Physical Fitness Percentiles of German Children Aged 9-12 Years: Findings from a Longitudinal Study. PLoS One 2015; 10(11): e0142393.

28. Cadenas-Sanchez C, Intemann T, Labayen I et al. Physical fitness reference standards for preschool children: The PREFIT project. J Sci Med Sport 2019; 22(4): 430-437. 
29. Roriz De Oliveira MS, Seabra A, Freitas D et al. Physical fitness percentile charts for children aged 6-10 from Portugal. J Sports Med Phys Fitness 2014; 54(6): 780-792.

30. Malina RM, Bouchard C, Bar-Or O. Growth, Maturation, and Physical Activity (2nd ed.). Champaign, IL: Human Kinetics, 2004.

31. Artero EG, España-Romero V, Ortega FB et al. Health-related fitness in adolescents: , and not only overweight, as an influencing factor. The AVENA study. Scand J Med Sci Sports 2010; 20(3): 418-427.

32. Ortega FB, Ruiz JR, Labayen I et al. Health inequalities in urban adolescents: role of physical activity, diet, and genetics. Pediatrics 2014; 133(4): e884-895.

33. Gontarev S, Kalac R, Velickovska LA et al. Physical fitness reference standards in Macedonian children and adolescents: the MAKFIT study. Nutr Hosp 2018; 35(6): 12751286.

34. Berk L. Development through the lifespan (6th ed.), Pearson Higher Education, Boston MA (2013)

35. Chen LJ, Fox KR, Haase A et al. Obesity, fitness and health in Taiwanese children and adolescents. Eur J Clin Nutr 2006; 60(12): 1367-1375.

36. Kim J, Must A, Fitzmaurice GM et al. Relationship of physical fitness to prevalence and incidence of overweight among schoolchildren. Obes Res 2005; 13(7): 1246-1254.

37. Brunet M, Chaput JP, Tremblay A. The association between low physical fitness and high body mass index or waist circumference is increasing with age in children: the 'Québec en Forme' Project. Int J Obes 2007; 31(4): 637-643.

38. Deforche B, Lefevre J, De Bourdeaudhuij I et al. Physical fitness and physical activity in obese and nonobese Flemish youth. Obes Res 2003; 11(3): 434-441.

39. Chen W, Lin CC, Peng CT et al. Approaching healthy body mass index norms for children and adolescents from health related physical fitness. Obes Rev 2002;3(3): 225-232.

40. Prista A, Maia JA, Damasceno A et al. Anthropometric indicators of nutritional status: implications for fitness, activity, and health in schoolage children and adolescents from Maputo, Mozambique. Am J Clin Nutr 2003; 77(4): 952-959.

41. Mak KK, Ho SY, Lo WS et al. Health-related physical fitness and weight status in Hong Kong adolescents. BMC Public Health 2010; 23:88. 


\section{Legends}

Table 1. Subject characteristics studied according to the sex

Table 2. Centiles estimation for cardiorespiratory fitness (20-m shuttle run test, meters) by sex and age in French children $(n=31484)$

Table 3. Centiles estimation for muscular strength (standing broad jump test, centimeters) by sex and age in French children $(n=31484)$

Table 4. Centiles estimation for speed (sprint test, meters) by sex and age in French children $(n=31484)$

Table 5. Centiles estimation for agility (hopscotch test, seconds) by sex and age in French children $(\mathrm{n}=31484)$

Figure 1. Physical fitness according to weight status in boys and girls (a. cardiorespiratory fitness ; b. speed; c. agility (log-transformed values are used to reduced the skewness of distribution); d. muscular strength). Values are age-adjusted mean and error bars represent standard deviation.

* Bonferroni-adjusted $\mathrm{p}<0.05$ for post-hoc pairwise comparisons with normal weight for girls $\dagger$ Bonferroni-adjusted $\mathrm{p}<0.05$ for post-hoc pairwise comparisons with normal weight for boys. Post-hoc comparisons were calculated using linear contrasts from ANCOVA model including age, sex, weight status and sex * weight status interaction.

Figure 2. Flexibility levels according to weight status in boys and girls

* Bonferroni-adjusted $\mathrm{p}<0.05$ for post-hoc pairwise comparisons with normal weight for girls (calculated using ordinal logistic regression including age, sex and IOTF)

${ }^{\dagger}$ Bonferroni-adjusted $\mathrm{p}<0.05$ for post-hoc pairwise comparisons with normal weight for boys

Supplemental File 1. Distribution (size) of the 31484 French children

Supplemental File 2. Diagnoform battery tests (DiagnoKid)

Supplemental file 3. Statistical analysis

Supplemental File 4. Physical fitness according to weight status in boys and girls

Supplemental file 5. Centile curves for the $10^{\text {th }}, 50^{\text {th }}$ and $90^{\text {th }}$ percentiles for cardiorespiratory fitness, agility, speed, and muscular strength. 
Table 1. Subject characteristics studied according to the sex

\begin{tabular}{|c|c|c|c|c|}
\hline & $\begin{array}{l}\text { Overall } \\
\mathrm{N}=31484\end{array}$ & $\begin{array}{l}\text { Boys } \\
\mathrm{N}=16023\end{array}$ & $\begin{array}{l}\text { Girls } \\
\mathrm{N}=15461\end{array}$ & $\begin{array}{l}\text { Standardized difference } \\
(95 \% \mathrm{CI})^{*}\end{array}$ \\
\hline \multicolumn{5}{|l|}{ Subject characteristics } \\
\hline Age, mean \pm SD & $8.6 \pm 1.5$ & $8.6 \pm 1.5$ & $8.6 \pm 1.5$ & $0.003(-0.02$ to 0.02$)$ \\
\hline $6-6.9$ years & $4006(0.13)$ & $2020(0.13)$ & $1986(0.13)$ & \\
\hline 7-7.9 years & $9373(0.30)$ & $4769(0.30)$ & $4604(0.30)$ & \\
\hline $8-8.9$ years & $6240(0.20)$ & $3209(0.20)$ & $3031(0.20)$ & \\
\hline $9-9.9$ years & $4653(0.15)$ & $2352(0.15)$ & $2301(0.15)$ & \\
\hline 10-10.9 years & $4832(0.15)$ & $2468(0.15)$ & $2364(0.15)$ & \\
\hline 11-11.9 years & $2380(0.08)$ & $1205(0.07)$ & $1175(0.08)$ & \\
\hline Weight $(\mathrm{kg})$, mean $\pm \mathrm{SD}$ & $30.1 \pm 8.7$ & $30.1 \pm 8.5$ & $30.1 \pm 8.9$ & $0.007(-0.01$ to 0.03$)$ \\
\hline Height $(\mathrm{cm})$, mean $\pm \mathrm{SD}$ & $132 \pm 10.3$ & $132 \pm 10.0$ & $132 \pm 10.6$ & $0.04(0.02$ to 0.07$)$ \\
\hline Body Mass Index $\left(\mathrm{kg} / \mathrm{m}^{2}\right)$, mean $\pm \mathrm{SD}$ & $17.1 \pm 3.1$ & $17.0 \pm 3.00$ & $17.1 \pm 3.1$ & $0.02(-0.006$ to 0.04$)$ \\
\hline \multicolumn{5}{|l|}{ Physical fitness } \\
\hline 20 -m shuttle run test $(m)$, mean $\pm \mathrm{SD}$ & $778 \pm 97.9$ & $792 \pm 100.9$ & $762 \pm 92.2 \dagger$ & $0.30(0.28$ to 0.32$) \ddagger$ \\
\hline Standing broad jump $(\mathrm{cm})$, mean \pm SD & $121 \pm 23.7$ & $126 \pm 24.0$ & $115 \pm 22.1 \dagger$ & $0.45(0.43$ to 0.47$) \ddagger$ \\
\hline Sprint test $(m)$, mean $\pm \mathrm{SD}$ & $23.3 \pm 3.2$ & $23.8 \pm 3.2$ & $22.7 \pm 3.1 \dagger$ & $0.33(0.31$ to 0.35$) \div$ \\
\hline Agility test ( $\mathrm{sec})$, mean $\pm \mathrm{SD}$ & $7.5 \pm 1.9$ & $7.7 \pm 2.0$ & $7.3 \pm 1.8 \dagger$ & $0.20(0.18$ to 0.22$) \ddagger$ \\
\hline Flexibility, median (IQR) & $4(3$ to 4$)$ & $3(3$ to 4$)$ & $4(3$ to 4$) \dagger$ & $0.41(0.39$ to 0.43$) \ddagger$ \\
\hline
\end{tabular}

Values are expressed in number (\%) unless otherwise indicated. * Cohen's d effect size.

$\uparrow \mathrm{p}<0.001$ for comparison in physical fitness parameters between boys and girls calculated using analysis of covariance (ANCOVA) or ordinal logistic regression (for Flexibility) adjusted for age and weight status. tcalculated from the ANCOVA model, adjusted for age and weight status (on rank-transformed data for flexibility).

Abbreviations : CI : Confidence interval ; IQR : interquartile range ; SD : standard deviation 
Table 2. Centiles estimation for cardiorespiratory fitness (20-m shuttle run test, meters) by sex and age in French children $(\mathrm{n}=31484)$

\begin{tabular}{|c|c|c|c|c|c|c|c|c|c|c|}
\hline & & \multicolumn{9}{|c|}{ Percentiles } \\
\hline & Mean \pm SD & 10 & 20 & 30 & 40 & 50 & 60 & 70 & 80 & 90 \\
\hline \multicolumn{11}{|l|}{ Boys } \\
\hline $6-6.9$ years & $745 \pm 85.6$ & 627 & 663 & 688 & 708 & 726 & 744 & 762 & 785 & 812 \\
\hline $7-7.9$ years & $782 \pm 88.1$ & 653 & 694 & 722 & 745 & 766 & 786 & 807 & 830 & 862 \\
\hline $8-8.9$ years & $791 \pm 103$ & 671 & 716 & 747 & 773 & 796 & 818 & 841 & 867 & 901 \\
\hline 9-9.9 years & $807 \pm 113$ & 682 & 731 & 764 & 792 & 816 & 840 & 864 & 892 & 929 \\
\hline $10-10.9$ years & $831 \pm 96.8$ & 688 & 739 & 773 & 802 & 827 & 851 & 877 & 905 & 944 \\
\hline $11-11.9$ years & $807 \pm 112$ & 691 & 741 & 775 & 803 & 828 & 852 & 877 & 905 & 942 \\
\hline \multicolumn{11}{|l|}{ Girls } \\
\hline $6-6.9$ years & $719 \pm 80.0$ & 620 & 654 & 676 & 695 & 712 & 728 & 745 & 764 & 790 \\
\hline $7-7.9$ years & $752 \pm 79.1$ & 638 & 675 & 700 & 721 & 739 & 757 & 776 & 796 & 824 \\
\hline $8-8.9$ years & $762 \pm 88.7$ & 653 & 694 & 721 & 744 & 764 & 783 & 803 & 826 & 856 \\
\hline 9-9.9 years & $774 \pm 105$ & 665 & 709 & 738 & 762 & 783 & 804 & 825 & 849 & 881 \\
\hline $10-10.9$ years & $797 \pm 91.2$ & 673 & 718 & 749 & 773 & 796 & 817 & 839 & 864 & 897 \\
\hline $11-11.9$ years & $781 \pm 107$ & 673 & 719 & 750 & 775 & 798 & 819 & 842 & 867 & 901 \\
\hline
\end{tabular}


Table 3. Centiles estimation for muscular strength (standing broad jump test, centimeters) by sex and age in French children $(\mathrm{n}=31484)$

\begin{tabular}{|c|c|c|c|c|c|c|c|c|c|c|}
\hline & \multirow[b]{2}{*}{ Mean \pm SD } & \multicolumn{9}{|c|}{ Percentiles } \\
\hline & & 10 & 20 & 30 & 40 & 50 & 60 & 70 & 80 & 90 \\
\hline \multicolumn{11}{|l|}{ Boys } \\
\hline $6-6.9$ years & $109 \pm 20.3$ & 78.2 & 86.6 & 92.6 & 97.7 & 103 & 107 & 113 & 119 & 127 \\
\hline $7-7.9$ years & $120 \pm 21.0$ & 88.1 & 96.8 & 103 & 109 & 114 & 119 & 124 & 130 & 139 \\
\hline $8-8.9$ years & $126 \pm 21.7$ & 96.8 & 106 & 113 & 118 & 124 & 129 & 135 & 141 & 150 \\
\hline $9-9.9$ years & $133 \pm 23.2$ & 104 & 113 & 120 & 126 & 132 & 137 & 143 & 150 & 160 \\
\hline $10-10.9$ years & $139 \pm 22.9$ & 108 & 118 & 125 & 131 & 137 & 143 & 149 & 156 & 166 \\
\hline 11-11.9 years & $138 \pm 24.5$ & 108 & 119 & 126 & 133 & 139 & 145 & 151 & 159 & 169 \\
\hline \multicolumn{11}{|l|}{ Girls } \\
\hline $6-6.9$ years & $100 \pm 19.1$ & 72.8 & 80.7 & 86.4 & 91.3 & 95.9 & 100 & 105 & 111 & 119 \\
\hline $7-7.9$ years & $110 \pm 19.7$ & 80.4 & 88.7 & 94.6 & 99.7 & 104 & 109 & 114 & 120 & 129 \\
\hline $8-8.9$ years & $114 \pm 19.8$ & 87.7 & 96.3 & 103 & 108 & 113 & 118 & 123 & 129 & 138 \\
\hline 9-9.9 years & $122 \pm 20.9$ & 93.8 & 103 & 109 & 115 & 120 & 125 & 131 & 137 & 146 \\
\hline $10-10.9$ years & $127 \pm 21.6$ & 97.9 & 107 & 114 & 120 & 125 & 130 & 136 & 143 & 152 \\
\hline $11-11.9$ years & $126 \pm 23.0$ & 98.7 & 108 & 115 & 121 & 127 & 132 & 138 & 145 & 155 \\
\hline
\end{tabular}


Table 4. Centiles estimation for speed (sprint test, meters) by sex and age in French children $(n=31484)$

\begin{tabular}{|c|c|c|c|c|c|c|c|c|c|c|}
\hline & \multirow[b]{2}{*}{ Mean \pm SD } & \multicolumn{9}{|c|}{ Percentiles } \\
\hline & & 10 & 20 & 30 & 40 & 50 & 60 & 70 & 80 & 90 \\
\hline \multicolumn{11}{|l|}{ Boys } \\
\hline $6-6.9$ years & $21.9 \pm 2.6$ & 18.0 & 19.1 & 19.8 & 20.5 & 21.08 & 21.7 & 22.3 & 23.1 & 24.1 \\
\hline $7-7.9$ years & $22.8 \pm 2.8$ & 18.8 & 20.0 & 20.9 & 21.6 & 22.25 & 22.9 & 23.7 & 24.5 & 25.7 \\
\hline $8-8.9$ years & $23.7 \pm 3.0$ & 19.7 & 21.0 & 21.9 & 22.7 & 23.40 & 24.1 & 24.9 & 25.8 & 27.1 \\
\hline 9-9.9 years & $24.9 \pm 3.1$ & 20.6 & 21.9 & 22.9 & 23.7 & 24.44 & 25.2 & 26.0 & 27.0 & 28.3 \\
\hline $10-10.9$ years & $25.5 \pm 3.0$ & 21.3 & 22.6 & 23.6 & 24.4 & 25.23 & 26.0 & 26.9 & 27.8 & 29.2 \\
\hline $11-11.9$ years & $25.7 \pm 3.3$ & 21.6 & 23.0 & 24.0 & 24.8 & 25.64 & 26.4 & 27.3 & 28.3 & 29.7 \\
\hline \multicolumn{11}{|l|}{ Girls } \\
\hline $6-6.9$ years & $20.9 \pm 2.6$ & 17.0 & 18.1 & 18.9 & 19.6 & 20.22 & 20.8 & 21.5 & 22.3 & 23.4 \\
\hline $7-7.9$ years & $21.9 \pm 2.7$ & 17.9 & 19.0 & 19.9 & 20.6 & 21.27 & 21.9 & 22.7 & 23.5 & 24.7 \\
\hline $8-8.9$ years & $22.5 \pm 2.9$ & 18.8 & 20.0 & 20.9 & 21.6 & 22.32 & 23.0 & 23.8 & 24.6 & 25.8 \\
\hline 9-9.9 years & $23.8 \pm 3.0$ & 19.7 & 20.9 & 21.8 & 22.6 & 23.28 & 24.0 & 24.8 & 25.6 & 26.9 \\
\hline $10-10.9$ years & $24.4 \pm 2.9$ & 20.4 & 21.6 & 22.5 & 23.3 & 24.04 & 24.8 & 25.6 & 26.5 & 27.7 \\
\hline $11-11.9$ years & $24.5 \pm 3.0$ & 20.8 & 22.1 & 23.0 & 23.8 & 24.51 & 25.2 & 26.0 & 27.0 & 28.2 \\
\hline
\end{tabular}


Table 5. Centiles estimation for agility (hopscotch test, seconds) by sex and age in French children $(\mathrm{n}=31484)$.

\begin{tabular}{|c|c|c|c|c|c|c|c|c|c|c|}
\hline & \multirow[b]{2}{*}{ Mean \pm SD } & \multicolumn{9}{|c|}{ Percentiles } \\
\hline & & 10 & 20 & 30 & 40 & 50 & 60 & 70 & 80 & 90 \\
\hline \multicolumn{11}{|l|}{ Boys } \\
\hline $6-6.9$ years & $9.2 \pm 2.4$ & 13.5 & 11.7 & 10.7 & 10.0 & 9.4 & 8.8 & 8.3 & 7.8 & 7.1 \\
\hline $7-7.9$ years & $8.2 \pm 2.0$ & 11.5 & 10.2 & 9.4 & 8.8 & 8.3 & 7.9 & 7.4 & 7.0 & 6.4 \\
\hline $8-8.9$ years & $7.7 \pm 1.8$ & 10.1 & 9.0 & 8.4 & 7.9 & 7.5 & 7.1 & 6.8 & 6.4 & 5.9 \\
\hline 9-9.9 years & $7.1 \pm 1.6$ & 9.2 & 8.3 & 7.7 & 7.3 & 7.0 & 6.7 & 6.3 & 6.0 & 5.6 \\
\hline $10-10.9$ years & $6.7 \pm 1.3$ & 8.6 & 7.8 & 7.3 & 7.0 & 6.6 & 6.4 & 6.1 & 5.8 & 5.4 \\
\hline $11-11.9$ years & $6.8 \pm 1.5$ & 8.5 & 7.7 & 7.2 & 6.9 & 6.5 & 6.3 & 6.0 & 5.7 & 5.3 \\
\hline \multicolumn{11}{|l|}{ Girls } \\
\hline $6-6.9$ years & $8.8 \pm 2.3$ & 13.0 & 11.2 & 10.2 & 9.5 & 8.9 & 8.4 & 7.9 & 7.4 & 6.7 \\
\hline $7-7.9$ years & $7.7 \pm 1.7$ & 10.6 & 9.5 & 8.8 & 8.3 & 7.9 & 7.5 & 7.2 & 6.8 & 6.3 \\
\hline $8-8.9$ years & $7.3 \pm 1.5$ & 9.2 & 8.4 & 7.9 & 7.5 & 7.2 & 6.9 & 6.6 & 6.2 & 5.9 \\
\hline $9-9.9$ years & $6.8 \pm 1.3$ & 8.4 & 7.7 & 7.3 & 6.9 & 6.6 & 6.4 & 6.1 & 5.8 & 5.5 \\
\hline $10-10.9$ years & $6.4 \pm 1.2$ & 8.0 & 7.3 & 6.9 & 6.6 & 6.4 & 6.1 & 5.9 & 5.6 & 5.3 \\
\hline $11-11.9$ years & $6.6 \pm 1.5$ & 8.0 & 7.3 & 6.9 & 6.6 & 6.3 & 6.0 & 5.8 & 5.5 & 5.2 \\
\hline
\end{tabular}

